\title{
Pure and mixed mucinous breast carcinomas: DNA stemline and prognosis
}

\author{
S TOIKKANEN, E EEROLA, ${ }^{*}$ T O EKFORS \\ From the Departments of Pathology and *Medical Microbiology, University of Turku, Finland
}

SUMMARY The DNA stemline of 45 mucinous breast carcinomas was determined by flow cytometry using paraffin embedded archival tissue sections. The material consisted of 26 pure mucinous and 19 mixed mucinous carcinomas. The patients were followed up for at least 15 years or until death. Nearly all pure mucinous carcinomas had a normal DNA stemline (25 of 26) with only one aneuploid tumour. Mixed mucinous carcinomas had a DNA content resembling that of common ductal carcinoma with 11 aneuploid tumours. Aneuploid tumours tended to be of higher grade and stage than diploid tumours. The survival of patients with pure mucinous carcinoma was better than that of patients with mixed mucinous carcinoma. Mucinous carcinoma should be classified as such only if it is a pure mucinous carcinoma.

DNA flow cytometry is a rapid and efficient method for evaluating the DNA content of tumour cells.' Although many mammary carcinomas have already been tested with this method, ${ }^{2-8}$ surprisingly little attention has been paid to different histological types. This is probably due to the fact that the most common type, infiltrating duct carcinoma, comprises most mammary cancers, and therefore material for study from other types is limited. We were able to find only eight reported cases of mucinous carcinoma of the breast measured by DNA flow cytometry. ${ }^{569}$

The method described by Hedley et al ${ }^{10}$ allows paraffin embedded archival material to be used in DNA flow cytometry, which helps considerably in prognostic studies. We report the results of the DNA flow cytometric analysis of 62 cases of pure or mixed mucinous mammary carcinomas followed up long term.

\section{Material and methods}

The cases were retrieved from the files of the department of pathology, University of Turku, Finland, and covered the period from 1945 to 1969 . Slides stained with van Gieson, haematoxylin and eosin, periodic acid Schiff with and without diastase treatment, high iron diamine-alcian blue and the Grimelius stain were reviewed. The tumours were divided into pure mucin-

Accepted for publication 3 September 1987 ous carcinomas and mixed mucinous carcinomas according to the following principles.

Pure mucinous carcinomas contained abundant extracellular mucin, which surrounded all the invasive cell groups at the tumour margins. Mixed mucinous carcinomas were similar in all other respects, but with a minor component of invasive cell strands without extracellular mucin - that is, they showed features of ductogenic carcinoma (figs 1 and 2).

As histological grading according to Bloom and Richardson" was difficult (because it emphasises the value of tubule formations) nuclear grade was determined according to Black and Speer instead. ${ }^{12}$ The clinical staging was performed according to the TNM system..$^{13}$ The patients were followed up for at least 15 years or until death. The cause of death was confirmed from various sources: necropsy; hospital files; the Finnish Cancer Registry; and the Central Statistical Office of Finland (cause of death statistics).

Single cell suspensions from paraffin blocks were prepared using the method described by Hedley et al. ${ }^{10}$ o In addition to the thick sections for DNA flow $N$ cytometry, a $5 \mu \mathrm{m}$ section was cut as a histological $\mathcal{N}$ control. The detached cells were treated with RNAse $(100 \mu \mathrm{g} / \mathrm{ml}$, Sigma Chemical Company, St Louis, Missouri, USA) for 15 minutes at room temperature and stained thereafter with propidium iodide $(416 \mu \mathrm{g} / \stackrel{\overparen{D}}{\stackrel{D}{+}}$ $\mathrm{ml}$, Sigma). The cells were then filtered through a $50 \mu \mathrm{m}$ nylon mesh to remove aggregates. The cells were analysed using an Epics-C clinical flow cytometer $\vec{D}$ (Coulter Electronics, Hialeah, Florida, USA). The excitation wavelength was $488 \mu \mathrm{m}$ at a power setting (a)

(1)




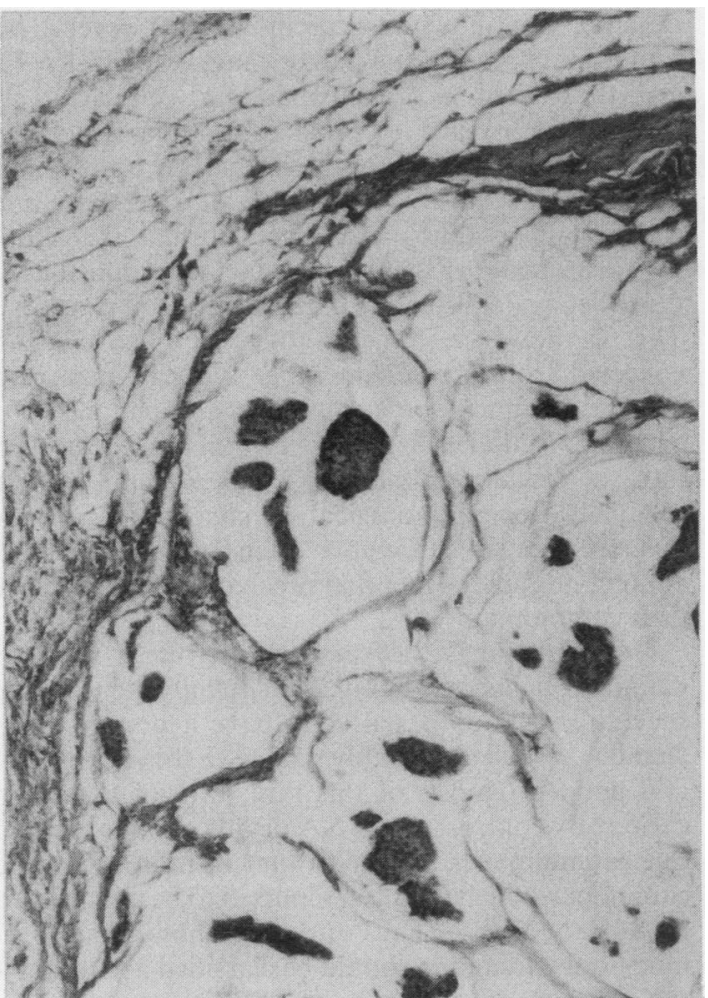

Fig 1 Pure mucinous carcinoma of the breast. All invasive cell clusters contain extracellular mucin.

of $400 \mathrm{~mW}$. Fluorescence was detected at a range of more than $570 \mu \mathrm{m}$. The minimum accepted cell number for each analysis was 5000 . The occurrence of cell aggregates was further elucidated by the use of an electronic gate in the channel detecting cell size (forward angle light scatter). The coefficient of variation averaged $6 \cdot 1$ for $G_{0} / G_{1}$ peak. Clear histograms were obtained from 45 tumours. In 17 tumours (13 pure mucinous carcinomas and 4 mixed mucinous carcinomas) the amount of intercellular mucin was so great that the cell number did not exceed the required 5000 cells, or the cell debris disturbed the histogram, and these tumours were therefore not regarded as eligible for the study. The first peak in the histogram (the lowest fluorescence intensity) was taken as the normal DNA stemline (diploid) and other peaks as the abnormal DNA stemline (aneuploid) except the peak at the tetraploid region if the cell number was less than $10 \%$. Because no control cells were used, hypoploidy could not be detected.

The Fischer-Irwin test was used for statistical analysis. $^{14}$

\section{Results}

Only one of the 26 pure mucinous carcinomas was aneuploid; 11 of 19 mixed mucinous carcinomas showed a cell line with abnormal DNA content. The difference was highly significant $(p=0.00007)$.

The clinical stage at the time of diagnosis was known in 44 cases. Table 1 shows the prevalence of diploid and aneuploid tumours at each stage. Aneuploid tumours tended to be of a higher stage. Mixed tumours were of a higher stage than pure tumours (table 1). Table 2 shows the correlation between nuclear grade and DNA stemline. The tumours with small and regular nuclei (grade III) were diploid in $90 \%$ of the cases, whereas only $58 \%$ of tumours with grades II and I nuclei (combined) had a normal DNA stemline.

One patient with a diploid tumour was lost to follow up and one with an aneuploid tumour died postoperatively. These patients were not included in the follow up data. In the diploid group there were six deaths from cancer; 15 patients died of other causes. Eleven patients were alive after 15 years. In the aneuploid group eight patients died of their cancer,

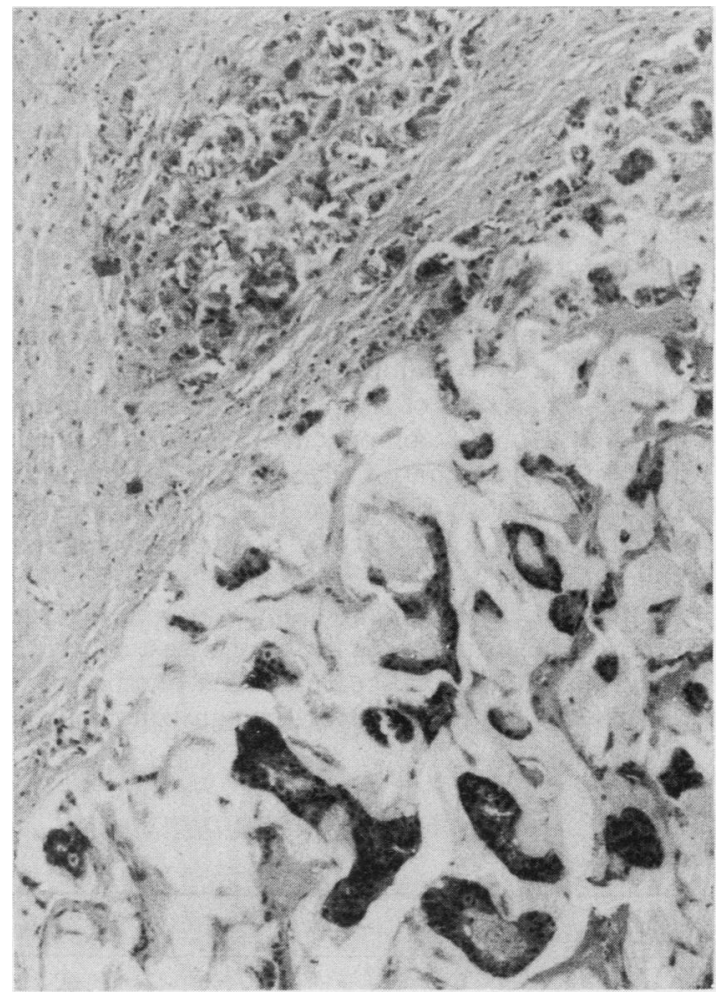

Fig 2 Mixed mucinous carcinoma of the breast. Infiltrating duct carcinoma comprises a minor component of tumour. 
Table 1 Distribution of tumours according to clinical stage at time of diagnosis

\begin{tabular}{lclcl}
\hline Stage & Diploid & Aneuploid & PMC & MMC \\
\hline I & 5 & & 4 & 1 \\
II & 16 & 3 & 13 & 6 \\
III & 8 & 7 & 6 & 9 \\
IV & 3 & 2 & 2 & 3
\end{tabular}

PMC, Pure mucinous carcinoma; MMC, mixed mucinous carcinoma.

two patients succumbed to other diseases, and only one was alive at the end of the follow up. Three patients with pure mucinous carcinoma and 11 patients with mixed mucinous carcinoma died of their cancer. This difference was significant $(p=0.001)$. Twenty two patients with pure mucinous carcinoma and seven with mixed mucinous carcinoma had no evidence of recurrent disease, were alive or had died of other causes.

\section{Discussion}

Our material comprised relatively advanced cancers, because many cases dated from the 50's and the 60's when patients sought medical treatment later than is usual today.

The DNA stemline of only a few mucinous carcinomas of the breast has been determined by DNA flow cytometry. Of the eight reported determinations that we found ${ }^{569}$ only one tumour showed abnormal DNA content, ${ }^{9}$ which agrees with our findings. Erhardt $e t$ $a l^{15}$ also reported abnormal DNA index using Feulgen microspectrophotometry in four of 13 colloid carcinomas of the breast. No information, however, was given in any of these reports as to whether the tumours contained areas resembling ordinary infiltrating carcinoma. The results of the present study show clearly that even a minor component of infiltrating ductal carcinoma is enough to change the DNA stemline and afford a prognosis similar to that of common ductogenic cancer. Rasmussen et al $^{16}$ recently reported similar findings based on histological features.

Mucinous mammary carcinoma has been regarded as one of the more benign forms of breast cancer, ${ }^{17-19}$ though this notion has recently been questioned. ${ }^{2021}$ The reasons for the relatively benign behaviour are

Table 2 Correlation of nuclear grade, DNA stemline, and histological type

\begin{tabular}{ccccc}
\hline Nuclear grade & Diploid & Aneuploid & PMC & MMC \\
\hline III & 19 & 2 & 13 & 8 \\
II & 12 & 9 & 11 & 10 \\
I & 2 & 1 & 2 & 1 \\
\hline
\end{tabular}

PMC, Pure mucinous carcinoma; MMC, mixed mucinous carcinoma. obscure, but mucinous carcinoma has several hise tological characteristics that may explain it. The growth pattern is often expanding, cellularity and: mitotic activity are low, and cell atypia is not ver $\overrightarrow{\vec{*}}$ prominent. In the light of these facts it was interesting to find that the DNA stemline of pure mucinous carcinoma was almost exclusively normal. It is tempto. ing to speculate that this is the factor responsible foo those benign features and consequent good prognosis This is, however, difficult to prove. The evidence collected from studies on other types of mammar $\vec{\phi}$ cancers includes some controversial findings. For example, medullary carcinoma of the breast seems tog have a prevalent abnormal DNA stemline despit relatively benign biological behaviour, ${ }^{6915}$ wherea? invasive lobular carcinoma often has normal DNA content despite the fact that it behaves like infiltrating duct carcinoma. ${ }^{15}$

Our material is too small to provide a basis foo definite conclusions, but it seems to indicate that pure mucinous carcinomas usually have a normal DNA stemline, which is probably related to the slow growt and good prognosis of this rare form of mammary cancer. By contrast, the DNA profile of mixed mucin $\vec{c}$ ous carcinomas is similar to that of infiltrating duc®o carcinoma, which has been reported to be abnormal in $60-80 \%$ of cases. ${ }^{27}$ Thus our study shows that mixe mucinous carcinoma should be classified according to the non-mucinous component of the tumour.

This study was financially supported by the Finnisi Foundation for Cancer Research.

\section{References}

1 Crissman MA, Steinkamp JA. Rapid simultaneous measuremenţ of DNA, protein and cell volume in single cells from large mammalian cell populations. J Cell Biol 1973;69:766-71.

2 Hedley IW, Rugg CA, Ng ABP, Taylor IW. Influence of cellula DNA content on disease-free survival of stage II breast cance $\bar{B}$ patients. Cancer Res 1984;44:5395-8.

3 Ewers SB, Långström E, Baldetorp B, Killander D. Flow-cytometric DNA analysis in primary breast carcinomas ans clinicopathologic correlations. Cytometry 1984;5:408-19.

4 Kute TE, Hyman B, Hopkins M, Marshall R, Case D, Kammire LO Relationship of flow cytometry results to clinical and steroidreceptor status in human breast cancer. Breast Cancer Treat $/ \mathbb{O}^{\circ}$ ment Res 1985;6:113-21.

5 McDivitt RW, Stone KR, Craig RB, et al. A proposed classifica N tion of breast cancer based on kinetic information. Derived from a comparison of risk factors in 168 primary operable $\underbrace{\omega}_{-}$
breast cancers. Cancer 1986;57:269-76.

6 Horsfall DJ, Tilley WD, Orell SR, Marshall VR, Cant ELo Relationship between ploidy and steroid hormone receptors in primary invasive breast cancer. $\mathrm{Br} J$ Cancer 1986;53:23-8.

7 Cornelisse CJ, van de Velde CJH, Caspers RCJ, Moolenaar $\mathrm{AJ}_{7}$ Hermans J. DNA ploidy and survival in breast cancer patients Cytometry 1987;8:225-34.

8 Owainati AAR, Robins RA, Hinton C, et al. Tumor aneuploidy prognostic parameters and survival in primary breast cancerळ Br J Cancer 1987;55:449-55. 
9 Olszewski W, Darzynkiewicz Z, Rosen PP, Schwartz MK, Melamed MR. Flow cytometry of breast carcinoma. I. Relation of DNA ploidy level to histology and estrogen receptors. Cancer 1981;48:980-4.

10 Hedley DW, Taylor IW, Rugg CA, Musgrove EA. Method for analysis of cellular DNA content of paraffin-embedded pathological material using flow cytometry. J Histochem Cytochem 1983;31:1333-5.

11 Bloom HJG, Richardson WH. Histological grading and prognosis in breast cancer. A study of 1409 cases of which 359 have been followed 15 years. Br J Cancer 1957;11:359-77.

12 Black MM, Speer FD. Nuclear structure in cancer tissues. Surg Gynecol Obstet 1957;105:97-102.

13 UICC. TNM classification of malignant tumours. Third ed. Union Internationale Contre le Cancer: Geneva, 1978:47-59.

14 Hodges IL Jr, Lehman EL. Basic concepts of probability and statistics. San Francisco: Holden-Day Inc, 1964:297-303.

15 Erhardt K, Auer G, Folin A, Silferswärd C, Skoog L. Mammary carcinoma: comparison between histologic type, estrogen receptor and nuclear DNA content. Am J Clin Oncol 1986;1:83-9.

16 Rasmussen BB, Rose C, Christensen . I. Prognostic factors in primary mucinous breast carcinoma. Am J Clin Pathol 1987; 87:155-60.

17 Lee YT. Surgical treatment of carcinoma of the breast: III. Pathological findings and probability of relapse. J Surg Oncol 1984;25:109-15.

18 Norris HJ, Taylor HB. Prognosis of mucinous (gelatinous) carcinoma of the breast. Cancer 1965;18:879-85.

19 Silverberg SG, Kay S, Chitale AR, Levitt SH. Colloid carcinoma of the breast. Am J Clin Pathol 1971;55:355-63.

20 Clayton FC. Pure mucinous carcinomas of breast: Morphologic features and prognostic correlates. Hum Pathol 1986;17:34-8.

21 Rosen PP, Wang TY. Colloid carcinoma of the breast: analysis of 64 patients with long-term follow-up. Am J Clin Pathol 1980;73:304.

Requests for reprints to: Dr S Toikkanen, Department of Pathology, University of Turku, Klinamyllynk 10, SF-20520 Turku 52, Finland. 